\title{
AIKALOSIS AND LOW PLASMA POTASSILM IN A CASE OF CUSHING'S SYNDROME: A METABOLIC STUDY
}

\author{
By DONALD M. WILlSON, MARSCHELLE H. POWER, AND EDWIN I. KEPLER \\ (From the Dizision of Biochemistry', The Mayo Foundation, and the Dizision of Medicine. \\ The Mayo Clinic. Rochester, Minn.)
}

(Received for publication April 29, 1940)

Addison's disease is characterized to a large degree by pathologic changes in the metabolism of electrolytes, but changes in the sexual organs and sexual characteristics either do not occur or are inconspicuous. In cases of Cushing's syndrome, ${ }^{1}$ on the other hand, demonstrable abnormalities in the metabolism of electrolytes occur only exceptionally, but changes in the sexual organs and sexual characteristics are the rule. In both diseases, amenorrhea or impotence may occur, although neither symptom occurs with regularity in cases of Addison's disease. In view of the fact that hyperplastic or neoplastic changes occur in the adrenal cortex with considerable regularity among cases of Cushing's syndrome, it is indeed remarkable that abnormalities of electrolyte metabolism occur so infrequently. In a series of more than thirty cases, thirteen of which were adrenal cortical tumor, we found only three cases in which there were marked changes in the electrolyte pattern of the blood. ${ }^{2}$ The first case of this type was reported by one of us in 1933 (1),

1 The term "Cushing's syndrome" is used here in the sense suggested by Kessel and refers to the clinical picture described by Cushing, namely hirsutism, amenorrhea or impotence, plethoric obesity, purplish striation, hypertension and osteoporosis. Cushing's syndrome has been found in association with basophilic tumors of the anterior pituitary body, neoplasms of the adrenal cortex and hyperplastic lesions of the adrenal cortices (sometimes in conjunction with thymomas). Cases have also been described in which necropsy findings have been extremely meager. In nearly all instances, Crooke's hyaline changes of the basophilic cells of the anterior pituitary body can be found. The term "Cushing's disease" refers to Cushing's syndrome that has occurred in association with a basophilic adenoma of the pituitary body.

2 In some of the earlier cases such changes were not sought with the care now possible as the result of improved chemical methods. Nevertheless, it is unlikely that such electrolyte changes were present, as the clinical picture that follows the disruption of the chemical constituents of the blood is as striking as the changes that occur when a patient suffering from Addison's disease experiences a "crisis." prior to our knowledge that the adrenal cortex was related to the metabolism of electrolytes. A few years later we published the findings concerning a second case $(2,3) .^{3}$ This report deals with our third case.

In 1937, McQuarrie. Johnson and Ziegler (4) studied and reported the electrolyte changes that occurred in another case. In all of these cases there was a severe alkalosis associated with a low concentration of chlorides in the plasma, and in McQuarrie's case, as well as in the present one, the concentration of potassium in the plasma was found to be low. (The plasma was not analyzed for potassium in the first two cases.) The occurrence of a low concentration of chloricles in the plasma in Cushing's syndrome has been a stumbling block in understanding the pathologic chemistry of this condition because, in contrast to Addison's disease, one might expect these chlorides to be increased, or at least normal.

The present study was undertaken in order to obtain more data as to the nature of the chemical changes that are associated with this syndrome.

Throughout the study the patient received a weighed diet low in content of sodium chloride and moderately high in potassium (approximately 4.0 grams of potassium, 0.6 gram of sodium and 1.0 gram of chloride) such as is used in the provocative test for the diagnosis of Addison's disease $(6,7)$. Additional salts (potassium citrate, potassium chloride or ammonium chloride) were administered in solution in divided doses during waking hours, or in the form of an 0.8 per cent

\footnotetext{
3 In both case reports alkalosis was mentioned but was not stressed. In the second case reported, death ultimately occurred and the findings at necropsy were reported by Norris (5). He felt that the primary lesion was an arrhenoblastoma of the ovary from which metastasis had occurred. This explanation scarcely accounted adequately for the events that took place during the patient's illness and was questioned by two competent histopathologists who subsequently examined sections of the tumor and the metastatic lesions.
} 


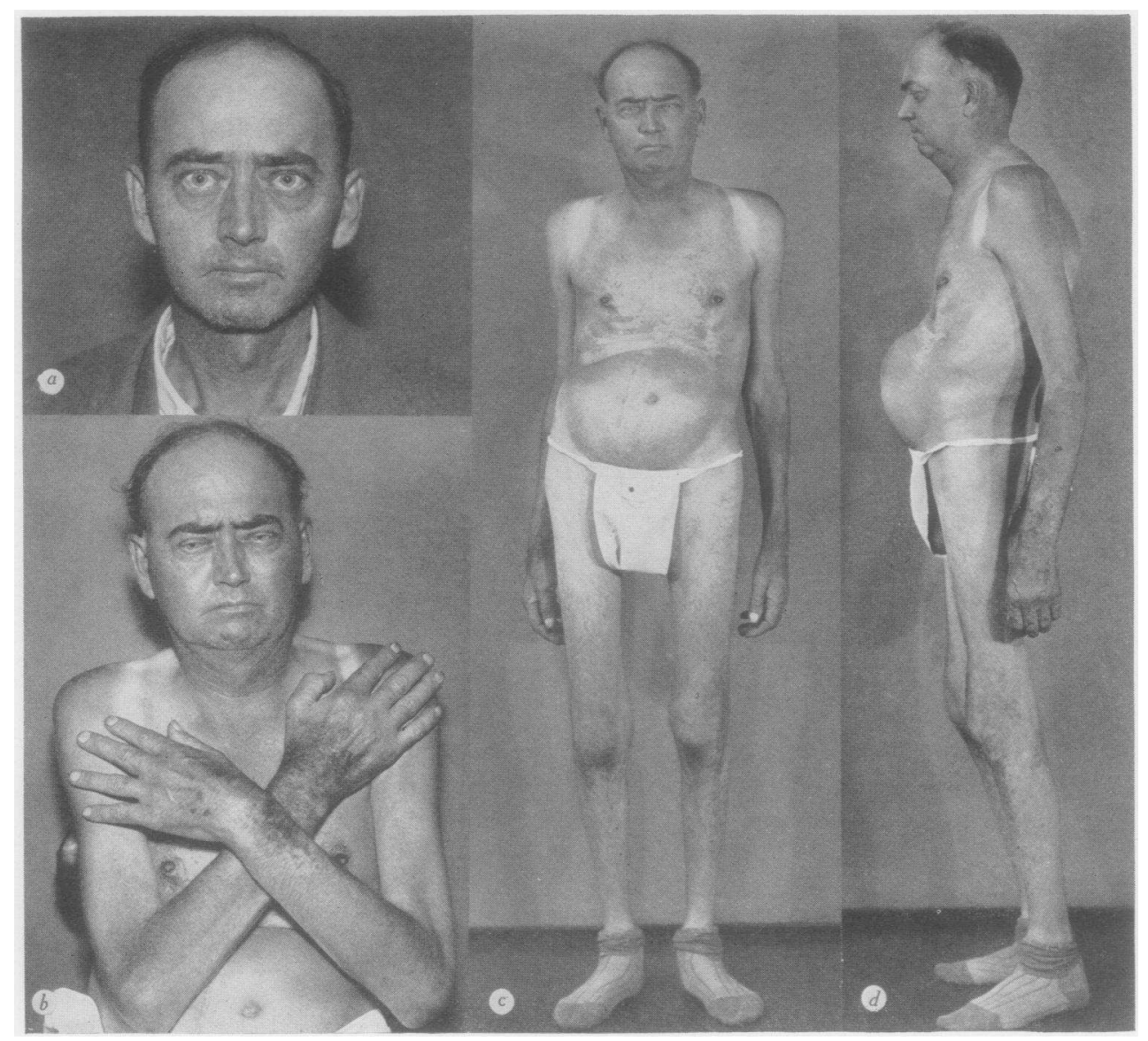

Fig. 1. Appearance of Patient

(a) October 17, 1938; (b), (c), and (d) August 28, 1939.

solution intravenously. Specimens of urine for each period of twenty-four hours were collected and were preserved with thymol in the refrigerator and aliquot portions were analyzed. Feces were separated into five- or seven-day periods by means of carmine markers, and aliquots were also analyzed for mineral components.

In the morning before the administration of food or salt solution, blood was collected under oil without the use of a tourniquet in order to avoid stasis. Heparin was used as anticoagulant. The specimens were chilled and analyses were begun immediately on the plasma.

\section{CHEMICAL METHODS}

The carbon dioxide content of the plasma as separated, and of another sample equilibrated at $38^{\circ} \mathrm{C}$. at a carbon dioxide tension chosen as closely as possible to that of separated plasma was determined by the method of Van Slyke and Neill (8). From these data the $\mathrm{pH}$ of the plasma as separated was calculated according to the method of Eisenman (9).

Chloride in plasma and in homogenized suspensions of feces was determined by a slight modification of the method of Keys (10), that in urine by the VolhardHarvey titration with the reagents described originally for plasma by Wilson and Ball (11). Sodium in plasma and urine was determined by the method of Butler and Tuthill as quoted by Peters and Van Slyke (12a), and potassium by the chloroplatinate method of Shohl and Bennett as modified by Hartzler (13). Feces were dried and powdered and weighed samples were ashed in an electric muffle overnight at $500^{\circ} \mathrm{C}$., after preliminary digestion with sulfuric acid. The ash was extracted with 0.5 normal hydrochloric acid and was analyzed for sodium and potassium by the methods cited.

The total nitrogen content of plasma, urine and homogenized suspensions of feces was determined by a modified Kjeldahl procedure.

\section{REPORT OF CASE}

A white, male farmer, aged thirty-nine years, first came to The Mayo Clinic on October 5, 1938, because 
of weakness, loss of weight and mental depression. The illness gradually developed during a period of six months and was punctuated by two episodes of transient painful edema of the face and lower extremities associated with paresthesias of the legs and fingers. Two months prior to admission diabetes and hypertension were first noted, and mental apathy, frequent spells of crying, and failure of memory became noticeable. Twenty-five pounds (11.3 $\mathrm{kgm}$.) were lost in the period of four weeks which preceded his coming to the clinic. In addition, there was a loss of libido of several months' duration. The use of alkalis or drugs was denied, and there had been no vomiting.

Physical examination revealed a negativistic, confused, dehydrated individual who appeared fifteen years older than his stated age and obviously was ill. He weighed 118 pounds $(53.6 \mathrm{kgm}$.). The blood pressure was 190 $\mathrm{mm}$. of mercury systolic and $110 \mathrm{~mm}$., diastolic. The temperature and respirations were normal and emphysema was not present. Some suggestion of a moon-face was evident, but there was comparatively little of the characteristic obesity or plethora of Cushing's syndrome (Figure 1a). There was no change in the secondary sexual characteristics; the breasts and testes appeared normal to palpation. Neurologic examination gave negative results; the cerebrospinal fluid contained $60 \mathrm{mgm}$. of protein per $100 \mathrm{cc}$. The basal metabolic rate was +16 per cent. The ocular fundi and visual fields were normal, as were also the excretory urogram and roentgenograms of the head. Roentgenoscopy failed to reveal any abnormality of the thymus.

The fasting blood sugar on admission was $173 \mathrm{mgm}$. per $100 \mathrm{cc}$. The blood sugar at 11 a.m. and 4 p.m. was $278 \mathrm{mgm}$. and $312 \mathrm{mgm}$. per $100 \mathrm{cc}$., respectively. The urine was usually sugar-free in the morning but moderate to severe glycosuria without ketonuria was present in the afternoon and evening. The daily administration of 20 units of protamine insulin practically eliminated the glycosuria. During the first six days of hospitalization prior to the observations to be reported (October 5 through 11, 1938), a marked negative fluid balance was present with urinary volumes averaging 4500 cc. daily on an intake averaging $3500 \mathrm{cc}$. This loss of fluid occurred even though glycosuria had been minimized by the use of insulin.

The most striking abnormalities observed were severe alkalosis (without signs of tetany) and the decrease in concentration of potassium in the plasma (Figure $2 d$ ).

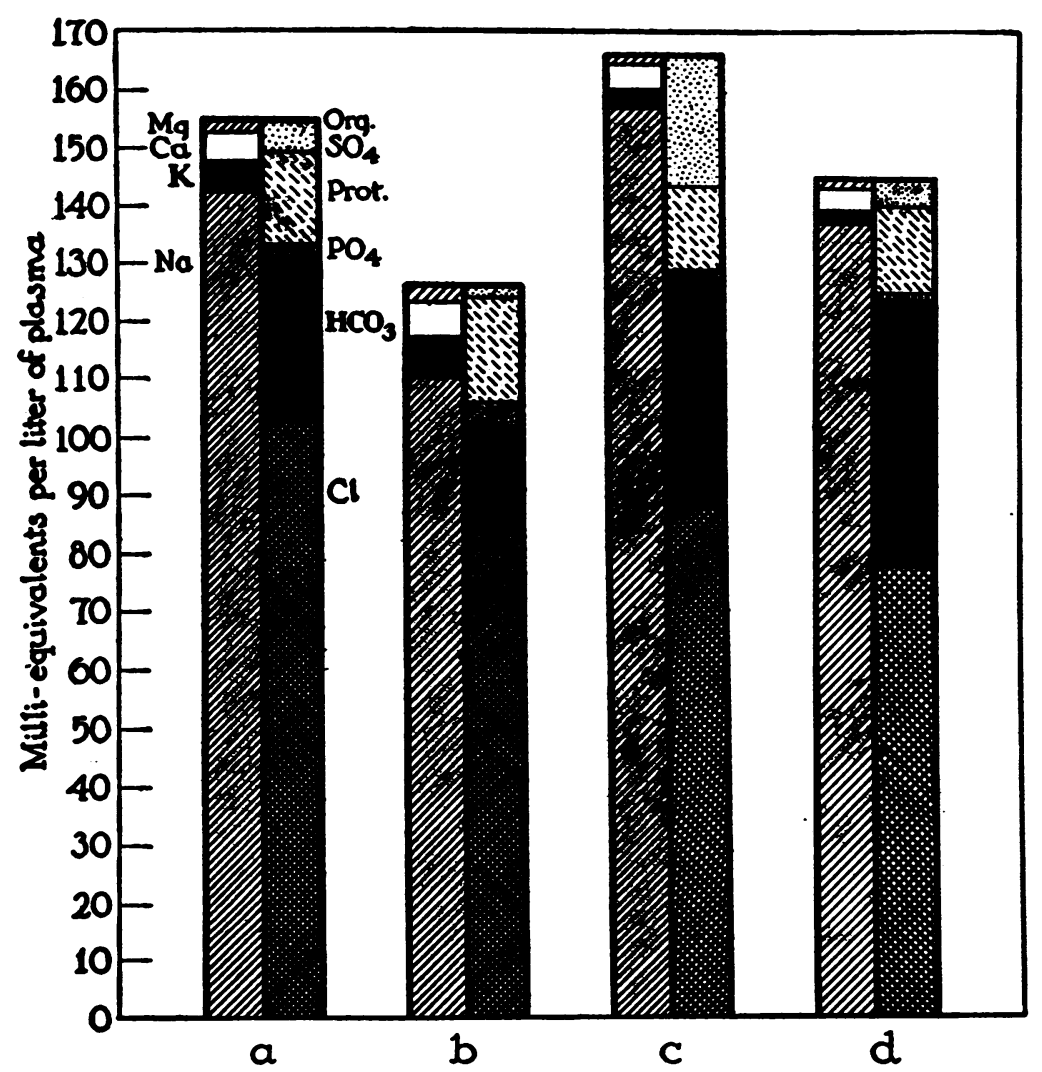

Fig. 2. Pattern of Electrolytes

(a) of a normal individual, (b) in an Addisonian crisis, (c) in a case of "hypercortico-adrenalism" and (d) in our own case of "hypercorticoadrenalism" herein reported (columns $a, b$, and $c$ are from McQuarrie (4)). 
TABLE I

Plasma electrolytes and average daiby metabolic balance in a case of Cushing's symdrome

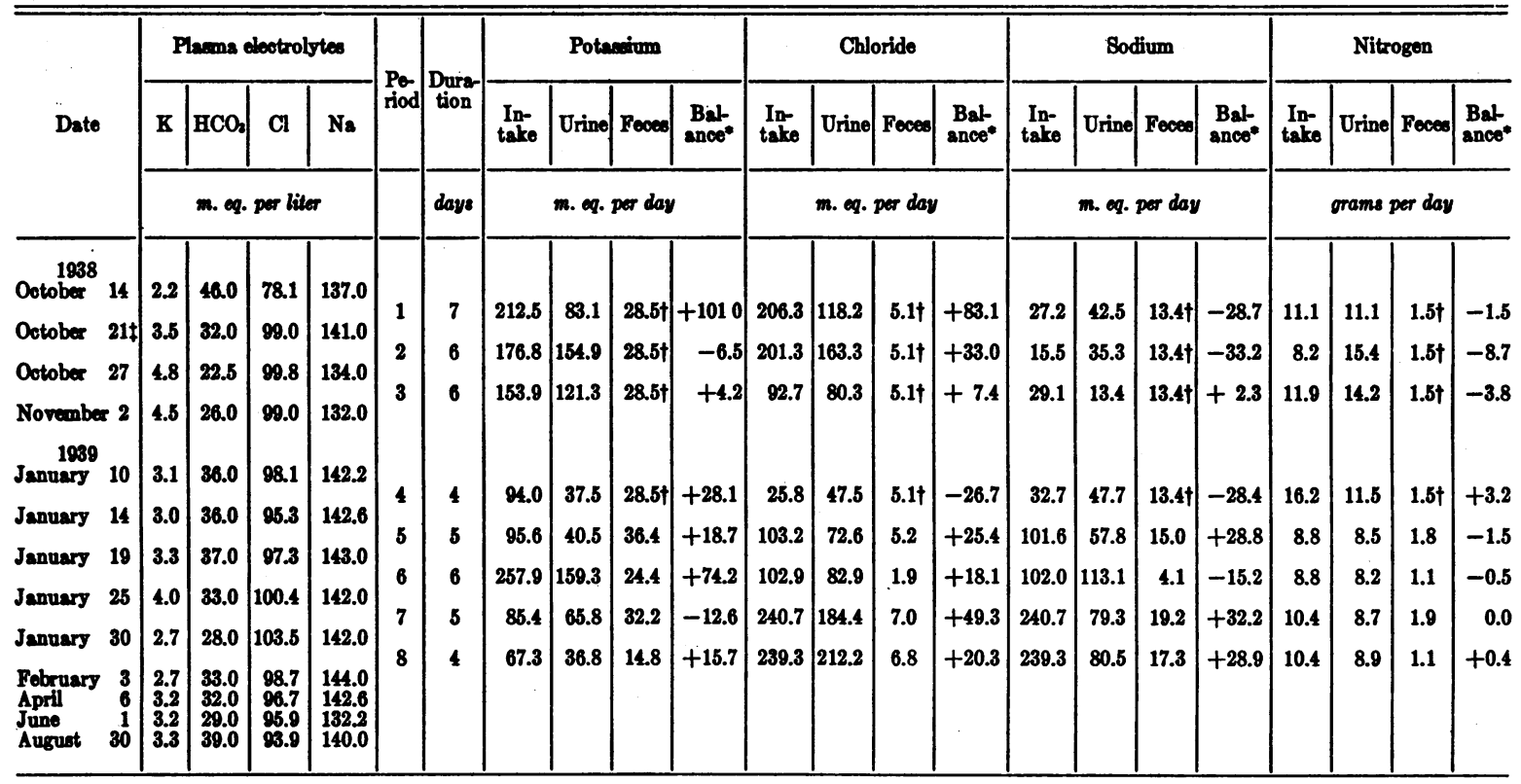

* Does not include unmeasurable loss through skin.

† Average of analyses, periods 5 to 8 , inclusive.

‡ Exploratory laparotomy on October 21.

On October 14, 1938, the electrolyte pattern of the plasma was as follows: Bicarbonate, 46 milliequivalents per liter; chlorides, 78.0 milliequivalents per liter; potassium, 2.2 milliequivalents per liter; and sodium, 137.0 milliequivalents per liter. The concentrations of calcium, magnesium, protein, inorganic phosphates, sulfates and urea were normal. An elevated concentration of sodium and a large undetermined acid fraction which McQuarrie found in the initial examination of his case of hypercortico-adrenalism were not present in this patient. Data concerning the method of correction of this disturbance are summarized in Table I.

During the first seven days (period 1) the patient received, daily, approximately 8 grams of potassium chloride and 3.5 grams of ammonium chloride in addition to the mineral salts that were present in the food. On this regimen there was an average daily retention of 3.95 grams of potassium and 2.48 grams of chloride (if the losses in the insensible perspiration are disregarded) and considerable improvement in the electrolyte pattern of the plasma occurred.

The patient was then subjected to an exploratory laparotomy (October 21) to exclude the possibility of an adrenal cortical tumor; the adrenal glands were normal to palpation and resection was not undertaken.

The metabolic studies continued uninterrupted by the surgical procedure and for the following six days (period 2) approximately the same intake of electrolytes was maintained. At the end of this period the electrolyte pattern of the plasma was essentially normal. A large negative nitrogen balance occurred postoperatively and there was also a slight negative balance for potassium and a small positive balance for chloride. This apparent loss of potassium is probably related to the loss of nitrogen incident to the surgical procedure and would probably have been of greater magnitude had not potassium been administered in excess.

In the succeeding period (period 3), after a normal electrolyte pattern of the plasma had been attained, the daily intake of electrolytes was reduced to 5 grams of potassium chloride plus the amounts present in the diet. The electrolyte pattern remained approximately normal and the patient maintained a state of metabolic balance. He was then dismissed and was instructed to follow a "qualitative" diabetic diet without regard to salt content in order to determine whether or not the disturbance of electrolytes would return.

During the aforementioned study, the severity of the diabetes decreased to the degree that it could be controlled by qualitative dietary restrictions without insulin. Similarly, the basal metabolic rate decreased to -9 per cent, but there was only slight improvement in the mental state, and the degree of hypertension was unaffected.

The patient returned for re-examination on January 9, 1939. In the interval his appearance had changed materially and for the first time it became definitely evident that his condition should be regarded as Cushing's syndrome. The face now was full, round and moon-like. The eyes were more protuberant and the characteristic adiposity of the trunk was present. Numerous hemangiomatous petechiae, 1 to $4 \mathrm{~mm}$. in diameter, were present on the face, dorsum of the hands, and conjunctivae. The blood pressure was $174 \mathrm{~mm}$. of mercury systolic and 114, diastolic. The urine was free of sugar and the 
concentrations of blood sugar were: at 8:00 a.m. (fasting) $101 \mathrm{mgm}$; at 11:30 a.m. $163 \mathrm{mgm}$; and at 4:00 p.m. $157 \mathrm{mgm}$. per cent. The tourniquet test (at 130 mm. mercury for ten minutes) gave negative results. The basal metabolic rate was -3 per cent, the sedimentation rate was normal and roentgenoscopy of the thorax again gave negative results. The electrolyte pattern of the plasma was again deranged (Table I), although not to the degree observed at the initial admission. At this time, the $\mathrm{pH}$ of the venous plasma, determined gasometrically, was found to be 7.54. This confirmed the previous impression that a state of uncompensated alkalosis existed.

Inasmuch as the results of the previous study had indicated that administration of potassium and chloride salts would correct the abnormal chemical composition of the blood, and that potassium chloride would maintain this correction, an effort was made to determine whether an excess of potassium or chloride ions individually would have a similar beneficial effect. Accordingly, the patient again received the basal diet previously described (period 4). The sodium chloride was increased, however, to approximately 6 grams daily (period 5). The concentration of electrolytes in the plasma remained essentially unchanged during these two control periods, except for a slight increase in the concentration of potassium which was accompanied by a slight retention of potassium. A negative balance for sodium and chloride in period 4 occurred, as one might expect, in a short period of sodium chloride restriction and the compensatory positive balance followed a return to an average intake of sodium chloride in period 5 .

The addition of 17.5 grams of potassium citrate per day to the diet (period 6) was associated with retention of a large amount of potassium, and the concentration of potassium in the plasma again increased. Coincidentally, there was a small but definite increase in the concentration of chloride in the plasma and a decrease in the concentration of bicarbonate in the plasma from the levels maintained during the two previous periods. This occurred in spite of the fact that no additional chloride ion was administered.

The substitution of 6 grams of ammonium chloride daily for the potassium citrate (period 7) resulted at first in a retention of chloride with a further increase in its concentration of the plasma and a decrease in concentration of bicarbonate. At the same time, however, a negative balance for potassium was observed and the concentration of the plasma potassium decreased to very low levels. Thereafter, in spite of continued administration of this same amount of ammonium chloride (period 8), the trend toward increasing concentrations of bicarbonate and decreasing concentrations of chloride in the plasma persisted. It would appear, therefore, that ammonium chloride was effective in the elevation of the concentration of chloride (and decrease in bicarbonate) in the plasma only when the concentration of potassium in the plasma was maintained near normal levels by the previous administration of potassium citrate.

The patient was observed at intervals following the completion of these observations and the electrolyte pattern remained reasonably well controlled (Table I) by the administration of 2 teaspoonfuls of potassium chloride daily. He finally discontinued this medication because of gastro-intestinal symptoms, however, and the final analysis of the blood on August 30,1939, revealed a derangement of the electrolyte pattern that was nearly as severe as that which was present at the original admission.

The development of the classical symptoms and signs of Cushing's syndrome continued in spite of four courses of roentgen therapy to the thymus and pituitary glands. The characteristic plethoric moon-face, adiposity and protuberant abdomen were present. In addition, osteoporosis and compression fractures of the spine developed and the patient decreased $10 \mathrm{~cm}$. in height within one year. A productive cough and paralysis of the left vocal cord, which developed following completion of the metabolic study, were suggestive of the possibility that a mediastinal lesion was present but this could not be confirmed.

Finally, weakness and cachexia developed (Figure $1 b$, $c$ and $d$ ), the diabetes became more severe, and the patient became bedfast and finally succumbed eighteen months after the onset of symptoms. Death occurred elsewhere and necropsy was not performed.

\section{COMMENT}

The striking abnormalities in the electrolyte pattern of the plasma of this patient consisted of an elevated concentration of bicarbonate, and a decreased concentration of chloride and potassium. In considering the bicarbonate-chloride relationship, the usual causes for such a disturbance were not present in this case. The possibility of a primary bicarbonate excess of respiratory origin is excluded by the observed $\mathrm{pH}$ of 7.54 (12b) and alkalosis resulting from administration of alkali or from loss of chloride by vomiting is likewise excluded. Apparently, the patient's condition represented an acid-deficit type of alkalosis of unusual origin.

The metabolic data indicate that, in addition to the persistently low value for potassium in the plasma, the intracellular stores of potassium were probably greatly depleted. During the initial seven-day period of study, the concentration of potassium in the plasma increased from 2.2 to 3.5 milliequivalents per liter. Such an increase would require, if equally distributed in the total body water (calculated as 70 per cent of the body weight), a retention of only about 2 grams of potassium. From the metabolic balance, however, it may be seen that 25.8 grams of potassium were retained, or (allowing for unmeasured loss 
through the skin) approximately ten times the amount calculated necessary to produce the observed increase in concentration in the extracellular water. This is in decided contrast to the small amount of potassium required to restore an equally diminished concentration of potassium in the plasma to normal in two cases of obstructing lesions of the colon in which treatment was by prolonged nasal suction with the Miller-Abbott tube. ${ }^{*}$ The recurrence of depletion of potassium in our case seems to be compatible with the results of recent investigations (14 to 19), which have shown that adrenal cortical extracts (and desoxycorticosterone) augment the urinary excretion of potassium when administered to normal or adrenalectomized animals or to patients who have Addison's disease.

The presence of a low concentration of chloride in the plasma is less easily understood. That it may in some way be conditioned by potassium, as suggested by McQuarrie (4), would seem to be supported by the fact that the concentration of both chloride and potassium in the plasma increased following the addition of potassium citrate to the diet, and by the failure of ammonium chloride alone to exert a beneficial effect on the concentration of chloride in the plasma, except when the concentration of potassium was normal. In this connection, it is of interest to note that the electrolyte pattern of the plasma of rats maintained on a diet deficient in potassium is in many respects similar to that seen in our case, that is, sodium relatively normal, but both chloride and potassium markedly decreased (20).

The absence of marked abnormalities in the concentration of sodium in the plasma or of changes in the metabolic balance of sodium is compatible with the picture of hypercorticoadrenalism. The formation of edema following the administration of large amounts of sodium salts or by the use of desoxycorticosterone in Addison's disease suggests that a moderate increase in the content of sodium within the body may be compensated for by an associated retention of water and thus may not be reflected by an increase in the concentration of this ion in the plasma. That an increase in the concentration of sodium

\footnotetext{
$\leqslant$ Unreported cases.
}

in the plasma may occur, however, was demonstrated in the initial analyses of the plasma in the case reported by McQuarrie and his co-workers and this increase represents the major difference in the electrolyte pattern in these two cases (Figure 2).

It would appear from these observations that the hypothesis of hypercortical adrenalism in our case is tenable and that this hyperfunction was responsible for a loss of potassium from the body.

\section{SUM MARY}

A typical case of Cushing's syndrome was studied because of the association of a disturbance in the electrolytes of the plasma, namely, diminished concentration of potassium and chloride, increased concentration of bicarbonate, elevated $\mathrm{pH}$, and normal concentrations of sodium, protein, calcium, magnesium, phosphorus and sulfates, and undetermined acid fraction.

The pattern of the plasma electrolytes returned to normal following the simultaneous administration of potassium chloride and ammonium chloride. Thereafter, the administration of potassium chloride alone maintained a relatively normal pattern.

The administration of potassium citrate was followed by partial correction of the abnormal concentrations of potassium, chloride and bicarbonate in the plasma.

Ammonium chloride failed to maintain a normal concentration of plasma chloride and bicarbonate after the concentration of plasma potassium decreased to low levels following discontinuance of administration of potassium salts.

The concentrations of other electrolytes in the plasma remained essentially normal throughout the period of observation and showed no apparent relation to the metabolic upset.

It is suggested that the abnormality in the distribution of electrolytes in this case is the result of the failure of the kidney to retain potassium, and that the chloride plays only a secondary rôle as it appears to do in cases of adrenal insufficiency.

The therapeutic administration of potassium chloride to this patient did not influence the course of the disease. 


\section{BIBLIOGRAPHY}

1. Kepler, E. J., Symposium: polyglandular dyscrasias involving abnormalities of sexual characteristics; report of four cases (case 4). Proc. Staff Meet., Mayo Clin., 1933, 8, 102-107.

2. Walters, W., Wilder, R. M., and Kepler, E. J., The suprarenal cortical syndrome: report of two cases, with successful surgical treatment. Proc. Staff Meet., Mayo Clin., 1934, 9, 400.

3. Walters, W., Wilder, R. M., and Kepler, E. J., Progress subsequent to subtotal bilateral suprarenalectomy for the suprarenal cortical syndrome. Proc. Staff Meet., Mayo Clin., 1934, 9, 661.

4. McQuarrie, I., Johnson, R. M., and Ziegler, M. R., Plasma electrolyte disturbance in patient with hypercorticoadrenal syndrome contrasted with that found in Addison's disease. Endocrinology, 1937, 21, 762.

5. Norris, E. H., Arrhenoblastoma; a malignant ovarian tumor associated with endocrinological effects. Am. J. Cancer, 1938, 32, 1.

6. Cutler, H. H., Power, M. H., and Wilder, R. M., Concentrations of sodium, chloride and potassium in the blood plasma and urine of patients with Addison's disease; their diagnostic significance. Proc. Staff Meet., Mayo Clin., 1938, 13, 244.

7. Cutler, H. H., Power, M. H., and Wilder, R. M., Concentrations of chloride, sodium and potassium in urine and blood; their diagnostic significance in adrenal insufficiency. J. A. M. A., 1938, 111, 117.

8. Van Slyke, D. D., and Neill, J M., The determination of gases in blood and other solutions by vacuum extraction and manometric measurement $\mathrm{J}$. Biol. Chem., 1924, 61, 523.

9. Eisenman, A. J., A gasometric method for the determination of $\mathrm{pH}$ in blood. J. Biol. Chem., 1927, 71, 611.

10. Keys, A., The microdetermination of chlorides in biological materials; presentation of a method and an analysis of its use. J. Biol. Chem., 1937, 119, 389.

11. Wilson, D. W., and Ball, E. G., A study of the estimation of chloride in blood and serum. J. Biol. Chem., 1928, 79, 221.

12a. Peters, J. P., and Van Slyke, D. D., Quantitative clinical chemistry. The Williams and Wilkins Company, Baltimore, 1932, Vol. II, pp. 732-736.

b. Peters, J. P., and Van Slyke, D. D., Quantitative clinical chemistry. The Williams and Wilkins Company, Baltimore, 1932, Vol. I, p. 944, Fig. 104.

13. Hartzler, E. R., A note on the determination of potassium by the method of Shohl and Bennett. J. Biol. Chem., 1937, 122, 19.

14. Thorn, G. W., Engle, L. L., and Eisenberg, H., The effect of corticosterone and related compounds on the renal excretion of electrolytes. J. Exper. Med., 1938, 68, 161.

15. Thorn, G. W., and Eisenberg, H., Studies on desoxycorticosterone; synthetic adrenal cortical hormone. Endocrinology, 1939, 25, 39.

16. Thorn, G. W., Howard, R. P., and Emerson, K., Jr., Treatment of Addison's disease with desoxycorticosterone acetate, a synthetic adrenal cortical hormone (preliminary report). J. Clin. Invest., 1939, 18, 449.

17. Harrison, H. E., and Darrow, D. C., Renal function in experimental adrenal insufficiency. Am. J. Physiol., 1939, 125, 631.

18. Ferrebee, J. W., Ragan, C., Atchley, D. W., and Loeb, R. F., Desoxycorticosterone esters; certain effects in the treatment of Addison's disease. J. A. M. A., 1939, 113, 1725.

19. Wilder, R. M., and his associates. Unpublished data.

20. Heppel, L. A., The electrolytes of muscle and liver in potassium-depleted rats. Am. J. Physiol., 1939, 127, 385. 